\title{
Conservadorismo, direitos, moralidades e violência: situando um conjunto de reflexões a partir da Antropologia*
}

Para Mariza Corrêa

Minha trajetória particular nesse percurso do feminismo aos estudos de gênero só ganha sentido, assim, se avaliada num contexto mais geral no qual a articulação entre militância política, pesquisa acadêmica e cenário político-cultural sejam levados em conta. E talvez seja bom lembrar, como antídoto às revisões históricas que acreditam numa imersão suave das feministas no meio acadêmico brasileiro, o mal estar que, ainda hoje, gera o interesse de pesquisa centrado nas mulheres. Lembro do comentário de um renomado antropólogo brasileiro ao assistir ao meu vídeo de pesquisa sobre a história da antropologia: "Interessante, mas tem muita mulher... (Corrêa, 2001:23-4).

* Agradecemos ao comitê editorial dos cadernos pagu o aceite desta proposta e o apoio e o incentivo de Antonio Carlos de Souza Lima (presidente da Associação Brasileira de Antropologia - ABA - na gestão 2015-16) e de Lia Zanotta Machado (presidenta da ABA na gestão 2017-18) à organização das atividades que deram origem a este dossiê e à sua publicação. A Maria Filomena Gregori agradecemos a colaboração na organização do simpósio especial Gênero, sexualidade, intolerância e violência na $30^{\mathrm{a}}$ RBA (João Pessoa, 2016) e o incentivo para a organização deste dossiê. Agradecemos também às/aos integrantes do Comitê Gênero e Sexualidade no biênio 2015-2016, que contribuíram ativamente para produzir todo o processo de reflexão aqui registrado. Nesse biênio, o comitê esteve composto pelos seguintes membros: coordenadora: Regina Facchini (Unicamp); vice-coordenador: Camilo Braz (UFG); Ana Paula da Silva (UFF); Cecilia Sardenberg (UFBA); Fátima Weiss de Jesus (UFAM); Flávio Luiz Tarnovski (UFMT); Heloisa Buarque de Almeida (USP); Paula Sandrine Machado (UFRGS); Lia Zanotta Machado (UnB); Rozeli Porto (UFRN); Sérgio Carrara (UERJ); e contou com colaborações constantes de Júlio Assis Simões (USP) e Adriana Piscitelli (Unicamp). Por fim, agradecemos o valioso trabalho do conjunto de pareceristas anônimos, que contribuiu de modo muito relevante para o adensamento e o aprimoramento dos artigos publicados neste dossiê. 
Há algumas décadas temos acompanhado transformações sociais importantes no que refere a gênero e sexualidade no Brasil e em toda a América Latina. Atualmente, gênero e sexualidade são não apenas identificados como dimensões centrais da vida social, como também têm galvanizado parte importante do debate político. A multiplicação e a renovada visibilidade de sujeitos políticos, suas lutas por reconhecimento como sujeitos de direitos e a oposição por parte de setores conservadores têm posicionado tais questões no centro de uma intrincada arena de disputas.

O olhar para os desafios políticos e intelectuais colocados pela articulação entre direitos, justiça, moralidades, conservadorismo, violência $e$ as ações e contrarreações de movimentos sociais no atual contexto têm mobilizado as atenções da comunidade científica delimitada pela Antropologia no campo dos estudos de gênero $e$ sexualidade nos últimos anos. Este dossiê procura retomar uma parte das reflexões que vêm sendo tecidas em fóruns da Antropologia no Brasil e em países vizinhos nos últimos dois anos, sem a pretensão de esgotar os debates desenvolvidos ou de fazer um completo mapeamento das questões envolvendo gênero e direitos sexuais na região. Interessa mais reunir contribuições que permitam refletir criticamente, questionando, a partir de recortes empíricos e aportes teóricos diversos, lugares comuns no delineamento das questões que nos ocupam, ajudando a configurá-los como problemas antropológicos.

Focalizamos, assim, uma série de questóes social $e$ politicamente relevantes e candentes no tempo presente: conservadorismos, direitos sexuais e reprodutivos, moralidades, violência. Este dossiê integra um processo de adensamento reflexivo que teve lugar no âmbito da atuação do Comitê Gênero e Sexualidade da Associação Brasileira de Antropologia (ABA), se desdobrando e aprofundando ao longo de suas duas últimas gestões. É também um capítulo vivo da história da produção de saberes antropológicos que não pode ser dissociado do compromisso com a defesa de direitos fundamentais de mulheres e de sujeitos situados a partir de suas sexualidades e expressões de gênero não normativas. Saberes que têm reconhecido seu papel 
no processo de "cidadanização" de mulheres e de pessoas LGBT na sociedade brasileira, que têm refletido sobre o "comércio" realizado nas fronteiras entre política e ciência $e$ suas especificidades no âmbito da Antropologia (Carrara, 2016) e cuja contribuição científica $e$ insights analíticos têm sido reconhecidos e apropriados inclusive por outras áreas do conhecimento.

\section{Situando o processo}

Em 18 de setembro de 2013, antropólogas/os pesquisadoras/es e estudantes encontraram-se no $10^{\circ}$ Seminário Internacional Fazendo Gênero (Florianópolis/SC) em reunião coordenada por Adriana Piscitelli, que então coordenava o Comitê Gênero e Sexualidade em colaboração com Sérgio Carrara. ${ }^{1}$ A reunião procurava orientar as próximas atividades do comitê e fez emergir dois conjuntos interconectados de demandas para a ação. Um primeiro dizia respeito à reflexão sobre o que constitui e quais as questões teóricas, metodológicas e éticas relacionadas à prática de uma antropologia feminista. Um segundo focalizava as relações entre Estado, fundamentalismos religiosos e laicos, direitos sexuais e reprodutivos e violência, considerando um contexto político que começava a dar mostras de retração nos processos de "cidadanização" de mulheres e de LGBT (Carrara, 2016). Naquele contexto também preocupava o cerceamento de direitos e o modo como esse processo incidia sobre a violência relacionada a gênero e sexualidade, inclusive em sua articulação com a deficiência, o envelhecimento e com populações indígenas e quilombolas. ${ }^{2}$

1 No biênio 2013-2014, esse comitê era composto por: Sérgio Luis Carrara (UERJ) (Coordenador); Adriana Piscitelli (UNICAMP) (Vice-coordenadora); Camilo Braz (UFG); Cecília Maria Bacellar Sardenberg (UFBA); Fátima Weiss de Jesus (UFAM); Flávio Luiz Tarnovski (UFMT); Paula Sandrine Machado (UFRGS); Regina Facchini (UNICAMP); Rozeli Maria Porto (UFRN).

2 Em resposta ao segundo conjunto de questões, no âmbito da $29^{a}$ Reunião da Associação Brasileira de Antropologia (Natal, RN, Brasil, 2014), o comitê em Gênero e Sexualidade organizou o Simpósio Especial intitulado: Antropologia, Direitos Sexuais e Fundamentalismos, sob a coordenação de Sérgio Carrara (UERJ) e Camilo Braz (UFG). A proposta desse simpósio foi dupla. Em primeiro lugar, pensar a 
$\mathrm{O}$ processo de aprofundamento da crise política que culminou com o afastamento da presidenta eleita Dilma Rousseff, $e$ a crescente restrição de direitos fundamentais no Brasil marcaram intensamente a gestão 2015-2016 da ABA. A centralidade com a qual questões envolvendo gênero, sexualidade $e$ moralidades se apresentaram nesse contexto traçou a continuidade e o aprofundamento das preocupações que já moviam a atuação de seu Comitê Gênero e Sexualidade desde a gestão anterior. Desse modo, as primeiras versões da maior parte dos artigos agrupados neste dossiê foram produzidas em paralelo à produção de textos de apoio à análise da conjuntura política ${ }^{3} e$ dos desafios que se colocavam para a atuação das/os antropólogas/os e de uma intensa ação de incidência política, marcada pela elaboração de várias notas públicas. ${ }^{4}$

questão dos fundamentalismos religiosos e laicos em relação aos desafios contemporâneos relativos à sexualidade, por meio de problematizações antropológicas em torno de temas como aborto, direitos LGBT, prostituição etc., bem como o uso de argumentos das ciências da saúde para legitimar argumentos religiosos. Discutia-se a própria noção de fundamentalismo e, caso seu uso se sustentasse, também se propunha pensar em suas vertentes laicas (racionalistas, universalistas), muitas delas formuladas na linguagem dos direitos, inclusive na dos direitos sexuais. Em segundo lugar, pretendeu-se discutir como os/as antropólogos/as articulam ou não, em seu fazer antropológico, o trabalho de pesquisa/produção intelectual e suas militâncias (convicções políticas e noções de cidadania) ou sua participação em processos governamentais e estatais (assessorias, consultorias, laudos, moções públicas). Tal tópico é um desdobramento de inquietações clássicas, que giram em torno das relações entre ciência, sociedade/cultura e poder/política.

3 Entre agosto e novembro de 2015, o Comitê de Gênero e Sexualidade trabalhou coletivamente, por solicitação da Presidência da $\mathrm{ABA}$, na produção de três textos de análise de conjuntura para o Informativo especial - conjuntura $n^{\circ}$ 01/2016 - Balanços parciais a partir de perspectivas antropológicas, disponível em: http://www.portal.abant.org.br/index.php/destaque/867-informativo-

especialconjuntura-n-01-2016-25-02-2016 (acesso em: 20 mai 2017). Os textos produzidos por esse comitê são: "Análise da atual conjuntura sócio-política referente à prostituição", assinado por Adriana Piscitelli (UNICAMP) e Ana Paula da Silva (UFF); "Questões sobre o debate social e político atual sobre família", assinado por Flávio Luiz Tarnovski (UFMT); e "Diversidade sexual e de gênero no contexto sócio-político brasileiro atual", assinado por Júlio Simões (USP), Regina Facchini (UNICAMP) e Sérgio Carrara (UERJ).

4 No período, a ABA, por meio do seu Comitê Gênero e Sexualidade, se manifestou a partir de uma série de processos legislativos que ameaçam os direitos fundamentais 
Este dossie inclui textos selecionados entre os apresentados na sessão Gênero, sexualidade e direitos: desafios políticos $e$ intelectuais contemporâneos do colóquio Gênero, classe, raça e sexualidade: desigualdades e desafios no campo dos direitos $\left(39^{\circ}\right.$ Encontro Nacional da ANPOCS, Caxambu, MG, Brasil, 2015); no simpósio Sexualidad y justicia: reconstruyendo una agenda de investigación (XI RAM - Reunião de Antropologia do Mercosul, Montevidéu, Uruguai, 2015) e no simpósio especial Gênero, sexualidade, intolerância e violência $\left(30^{\mathrm{a}}\right.$ Reunião Brasileira de Antropologia, João Pessoa, PB, Brasil, 2016). ${ }^{5}$

\section{Conservadorismo, direitos e moralidades}

$\mathrm{O}$ atual embate conservador contra as conquistas e a visibilidade de movimentos de minorias parece constituir hoje um dos principais obstáculos para a garantia dos direitos fundamentais de uma série de sujeitos. $\mathrm{O}$ foco na moral sexual da agenda conservadora tem tomado como alvo especialmente os direitos relacionados à equidade de gênero e à diversidade sexual e de gênero. Por um lado, decorrente da crescente pluralidade religiosa do Brasil, e de uma diversidade de visões e interpretações da laicidade do Estado, atores cristãos têm conseguido uma expressiva representação pública. Marcando uma virada a respeito das formas clássicas de influência da Igreja Católica, lideranças do campo evangélico pentecostal têm se lançado massivamente à política e disputando cargos eletivos, principalmente como

de mulheres e de LGBT, tais como o Projeto de Lei n. 6.583/2013, que prevê a criação do Estatuto da Família, o processo de exclusão de gênero nos planos estaduais e municipais de educação e o Projeto de Lei n. 5069/2013, que altera a abrangência $e$ as formas de atendimento e de oferta de prevenção à gravidez para mulheres vítima de violência sexual. O relatório de atividades desse comitê nessa e em outras gestões $e$ a íntegra das notas $e$ moções estão disponíveis em: http://www.portal.abant.org.br/index.php/22-quem-somos/118-comite-genero-esexualidade (acesso em 20 mai. 2017).

5 Essas atividades foram organizadas, respectivamente, por Regina Facchini; por Horacio Sívori; e por Horácio Sívori, Maria Filomena Gregori e Regina Facchini, sendo que a sessão no colóquio da $29^{\circ}$ Encontro Anual da ANPOCS e o simpósio especial na $30^{\mathrm{a}}$ Reunião Brasileira de Antropologia foram apoiadas pela $\mathrm{ABA}$ por meio de seu Comitê Gênero e Sexualidade. 
legisladores, predominantemente a partir de partidos de centrodireita. Organizados como bancada no Congresso Nacional, na sua atuação pública, parte importante desses parlamentares evoca uma visão idealizada de unidade do "povo de Deus" como suposta maioria nacional para agitar ansiedades morais com um relato apocalíptico no qual os direitos e políticas para as mulheres e LGBT, além de cercear a liberdade religiosa, ameaçariam a integridade moral das crianças e da família brasileira.

Para analisar o que se tem referido como uma "virada conservadora" no Brasil, o artigo de Ronaldo de Almeida (2017), "A onda quebrada: evangélicos e conservadorismo", nota que termos como "conservadores", "fascistas", "fundamentalistas", bem como as referências generalizantes a "os evangélicos", construídos relacionalmente no debate público, circunscrevem "um conjunto relativamente variado de discursos, valores, ações e posicionamentos políticos com interesses parcial $e$ conjunturalmente comuns". Estes últimos se constituem por meio de linhas de força que estabelecem conexões parciais entre "evangélicos" e "conservadorismo". No vetor econômico, se celebra a meritocracia e o empreendedorismo; no vetor da moralidade pública, se impóe uma agenda reguladora e restritiva; no âmbito das demandas e da movimentação política, demandam-se políticas de segurança mais punitivas e repressivas; $e$, por fim, no que se refere à qualidade e à intensidade das interações sociais em situações de forte antagonismo político, se produzem manifestações de intolerância social.

No plano das estratégias argumentativas do atual "giro conservador" católico, o artigo "La Iglesia Católica frente a la política sexual: la configuración de una ciudadanía religiosa", de Juan Marco Vaggione (2017), refere um processo complementar do "secularismo estratégico", já descrito pelo autor (Vaggione, 2013): a intensificação do uso de argumentações e formas de atuação seculares para potencializar o impacto da Igreja através do direito. A "cidadania religiosa" diz respeito a um processo de reconfiguração da cidadania determinada pelo religioso, tendo como eixo articulador a defesa de uma ordem moral universal na 
mobilização e na proteção das crenças religiosas em oposição aos direitos sexuais e reprodutivos. As figuras do "cidadão" e do "crente" se imbricam, nesse ativismo, de três modos: na defesa de uma comunidade moral ameaçada pela "cultura da morte" e a "ideologia de gênero"; na mobilização dos cidadãos enquanto crentes em defesa de uma ordem sexual e social; e na reinterpretação e expansão do alcance da "liberdade religiosa" $e$ da "objeção de consciência" como estratégia de resistência à "sexualização da cidadania".

A agenda que se contrapõe a direitos fundamentais relacionados a gênero e a sexualidade é conduzida hoje por uma aliança inédita de católicos, de evangélicos e de outras bancadas conservadoras no poder legislativo, que recicla argumentos condensados em mensagens papais e estratégias políticas desenvolvidas internacionalmente por intelectuais $e$ ativistas católicos na década de 1990, já em resposta às mudanças trazidas pelas conferências de Cairo e de Beijing. Passou a destacar-se nos últimos anos nessa produção intelectual e nas estratégias políticas desses atores o investimento em campanhas contra o que eles convencionam denominar "ideologia de gênero". O construto é formulado de modo a situar a teorização sobre as desigualdades e as políticas pela equidade e contra a discriminação no registro da opinião, da ideologia como inverdade, do não comprovado pela ciência, contrário à lei positiva - que nessa perspectiva é indistintamente alinhada à lei natural.

A reprodução biológica continua sendo um bastião da resistência conservadora contra o feminismo. O artigo de Lia Zanotta Machado (2017), "O aborto como direito e o aborto como crime: o retrocesso neoconservador", analisa o confronto político entre argumentações feministas e fundamentalistas sobre o aborto, no Brasil dos anos 2000. Situa disputas por concepções de vida nas quais feministas defendem a distinção entre "vida vivida" $e$ "vida abstrata". Fundamentalistas, por outro lado, sustentam os direitos absolutos do concepto desde a fecundação e que o aborto deveria ser crime em qualquer circunstância. A análise de depoimentos de parlamentares indica confronto com a laicidade 
do Estado a partir de uma articulação de narrativas religiosas, jurídicas e científicas. A narrativa religiosa constrói o argumento da legitimidade da maioria religiosa cristã na sociedade brasileira. A narrativa jurídica do direito absoluto da vida do concepto reitera a subordinação da "posição da mulher" na "famillia tradicional". A narrativa científica, tal como apropriada pela narrativa religiosa, articula a descoberta da singularidade individual do DNA à singularidade da alma individual. Desse modo, a imposição de valores morais e religiosos para toda a sociedade implica o retrocesso dos direitos ao aborto, como também dos direitos das mulheres.

Esse investimento conservador se sofistica em contextos nos quais se aborda a ambígua regulação do avanço tecnomédico no campo da reprodução assistida. O artigo de Lucia Ariza (2017), "La regulación de las tecnologías reproductivas y genéticas en Argentina: análisis del debate parlamentário", analisa o debate parlamentar em torno da regulação das tecnologias reprodutivas $e$ genéticas na Argentina, país que recentemente sancionou uma Lei de Reprodução Medicamente Assistida e novo Código Civil e Comercial. Na primeira, uma concepção ampla do "direito à procriação" torna-se inteligível apenas em função de uma ideia de família cis-heterossexual, na qual a maternidade é tida como o evento mais central da vida das mulheres cisgêneras. No debate do segundo, o conservadorismo religioso fusionou semanticamente a noção de vida $e$ a de pessoa, outorgando à primeira valências e direitos próprios da segunda. Instrumentalizando a linguagem secular dos direitos, essa visão fez com que a definição de pessoa humana constante do novo Código Civil se dê nos termos definidos pela Igreja Católica.

No Brasil "ideologia de gênero" foi a categoria em pauta para eliminar a "superação da desigualdade racial, regional, de gênero e orientação sexual" das diretrizes do Plano Nacional de Educação, cuja aprovação final, na Lei 13.005 em junho de 2014, se deu sem essa menção. O construto é retomado no artigo de Naara Luna (2017), "A criminalização da 'ideologia de gênero': uma análise do debate na Câmara dos Deputados sobre diversidade sexual em 2015". A autora relata que entre os mais 
atuantes nesses debates estão parlamentares com identidade religiosa definida e cuja atuação nesses embates serve à construção ou ao reforço dessa identidade religiosa, bem como do caráter público da religião. Nesse contexto a expressão "ideologia de gênero" é utilizada como categoria acusatória cuja censura serve para bloquear avanços legislativos relacionados à diversidade sexual e de gênero, inclusive por meio da criminalização de condutas, do manejo de pânicos morais e da distorção de argumentos científicos.

O empreendedorismo moral de lideranças religiosas e sua capacidade para mobilizar pânicos sexuais e gerar mudanças do discurso oficial do Estado laico sobre política sexual chamam atenção para a complexidade desse campo diante do atual desafio de produzir uma aproximação pluralista à sexualidade. No campo da educação pública, o artigo de Marcos Castro Carvalho e Horacio Sívori (2017), "Conservadorismo religioso, gênero e sexualidade na política educacional brasileira", observa uma dupla articulação de lideranças católicas e evangélicas para a imposição dos seus preceitos morais. Desenvolve-se uma atuação positiva, no sentido de fomentar e difundir valores próprios por meio de uma interpretação confessional do ensino religioso estrategicamente oficializado na ordem jurídica brasileira; e uma atuação negativa, na direção de um cerceamento, restrição $e$ deslegitimação de valores tidos como antagônicos.

Moral religiosa e liberdade sexual são intrinsecamente opostas? A produção científica é patrimônio exclusivo da esfera secular? Todo direito democrático deve ter base científica? As autoras e os autores deste dossiê interrogam cada um desses lugares comuns de modo a torná-los problemas antropológicos. Para compreender as condições que tornam possível essa nova virada conservadora parece necessário se deslocar das oposições secular/religioso, laico/religioso, científico/religioso, políticojurídico/religioso ou mesmo estatal/eclesial; e perguntar então que outras categorias analíticas poderiam subsidiar sua abordagem.

Duas contribuições deslocam o foco da oposição secular/religioso, para interrogar supostos morais ancorados em 
teorias e práticas sociais em torno do valor econômico e social do trabalho. O artigo de Ana Paula da Silva e Thaddeus Gregory Blanchette (2017), "Por amor, por dinheiro? Trabalho (re)produtivo, trabalho sexual e a transformação da mão de obra feminina", traz elementos para refletir sobre os conceitos de trabalho e trabalho de mulher. A consideração do trabalho sexual como uma variante do trabalho reprodutivo ainda provoca grandes polêmicas entre parcelas significativas dos movimentos sociais "progressistas" e dos setores religiosos conservadores, dificultando seu reconhecimento como uma ocupação legítima. O texto explora algumas possibilidades analíticas com relação ao desconforto gerado pelo trabalho sexual - apenas ele, apartado de outros tradicionais trabalhos reprodutivos "feitos por amor" - em grupos políticos e sociais tão heterogêneos.

O artigo "La travesti permitida y la narcotravesti: imágenes morales en tensión", de María Soledad Cutuli (2017), observa um "giro conservador" nas imagens públicas gestadas em torno das travestis na Argentina. A ideia de "trabalho digno" mobilizada por políticas de inclusão laboral é associada também, nesse contexto, a um paradigma abolicionista que considera a prostituição uma forma indigna de exploração em qualquer circunstância. Em contraposição, a imagem da "narcotravesti", racializada $e$ associada ao mundo do delito, condensa também a estigmatização de migrantes de países vizinhos. O artigo explora, por um lado, as intersecções políticas e morais que demarcam os limites do possível e do aceitável para as travestis; e, por outro, a configuração de vulnerabilidades diferenciais em um contexto de retrocesso e de pauperização de suas condições de vida.

\section{A violência como dispositivo de produção de sujeitos morais}

As questões que articulam gênero e violência têm passado por intensos processos de transformação no Brasil nas últimas décadas. Tais mudanças, conforme argumentam Facchini $e$ Ferreira (2016), articulam uma série de processos políticos e sociais. Os anos 2000 apresentam um ponto de inflexão importante, não apenas pela criação de órgãos de gestão, mas 
pela ampliação das formas de participação, com a convocação de conferências de políticas para as mulheres, que foram base para a elaboração de planos nacionais de políticas para as mulheres. A partir da articulação de ações governamentais e do movimento feminista, é promulgada a Lei Maria da Penha (2006) e são implantados sistemas de notificação de violência contra a mulher. Em 2009, a tipificação penal de estupro foi alterada, permitindo abranger outras práticas tidas como sexuais para além da penetração vaginal (Machado, 2016).

Paralelamente, há uma alteração dos regimes de visibilidade dos feminismos possibilitada pela crítica à centralidade da atuação institucional, que dá lugar à emergência de grupos e coletivos que apostam em discursos e "modos de fazer" mais horizontais, resultando em uma multiplicação de campos feministas $e$ pluralização das práticas (Facchini; França, 2011; Alvarez, 2014). A popularização do uso da internet e da possibilidade de produção de conteúdo por usuárias faz com que repertórios feministas alcancem maior disseminação, aprofundando contatos entre organizações políticas e grupos já existentes, mas também cria outras conexões político-digitais (Ferreira, 2015). A partir de 2011, por meio de articulações transnacionais facilitadas pela internet, emergem ocupações do espaço público coordenadas por redes político-comunicacionais feministas (principalmente a partir de blogs, Facebook e Twitter). Eventos como as Marchas das Vadias se consolidam na agenda de combate à violência e dão lugar à constituição de coletivos locais com reuniões presenciais, estabelecendo-se como nódulos relevantes em meio a essa teia político-comunicacional (Facchini; Ferreira, 2016).

De acordo com Facchini e Ferreira (2016), tais processos articulados implicam significativas alterações dos regimes de visibilidade dos feminismos e da violência relacionada a gênero, bem como mudanças nas convenções que implicam a percepção, o reconhecimento e o enfrentamento à violência. Essa reflexão se articula, e toma por base, a pesquisa em desenvolvimento por Heloisa Buarque de Almeida a partir das denúncias de várias formas de violência, incluindo a violência sexual, em âmbito 
universitário. Tais denúncias acabaram ganhando destaque especialmente pelos estupros, mas também por rituais de iniciação, os trotes, em cursos mais antigos e tradicionais.

No artigo publicado neste dossiê, "De médico e de monstro: disputas em torno das categorias de violência sexual no caso Abdelmassih", Heloisa Buarque de Almeida (2017) explora as narrativas mobilizadas no processo jurídico envolvendo o médico Roger Abdelmassih e em sua divulgação na mídia. A reflexão tecida pela autora traz pistas para entender os embates em torno de categorias para referir violência sexual, seus efeitos nas normatividades de gênero e formas de definir o que constitui violência e na produção de sujeitos morais. As controvérsias suscitadas por atuações e condutas que, embora públicas, apelam a questões e dilemas que implicam o âmbito do privado, apontam para novas (e algumas renovadas) disputas em torno de locais $e$ modos de regulação moral e biopolítica.

Além de abusos contra moças e rapazes em eventos coletivamente organizados, como os trotes universitários, vem adquirindo vulto, na esfera pública, uma variedade de manifestações de homofobia, agressões físicas, muitas vezes letais, contra gays, lésbicas, bissexuais e pessoas trans, assassinatos e/ou estupro de mulheres turistas, bem como formas de assédio público vividas por profissionais do sexo. Em parte desses episódios, salta à vista que o abuso é cometido por um grupo ou apoiado por instâncias que implicam coletividades organizadas.

Contudo, as teorizações de maior visibilidade e impacto sobre violência no campo dos estudos de gênero e sexualidade versam sobre relações interpessoais ou as que ocorrem em meio à família, relações de parentesco e na esfera doméstica (Gregori, 2010). Parece rentável uma visada teórica mais arrojada de modo a entender melhor como operam essas violências em um âmbito público e também a explorar o que atravessa de modo semelhante violências que têm sido estudadas de forma segmentada: violência contra mulheres, homofobia, transfobia, racismo. Notamos uma significativa fragilidade nas teorias correntes em lidar com o fato de que essas violências (que na ausência de um termo melhor, 
estamos chamando de públicas) operam no cenário político e social de expansão dos direitos sexuais, expressando uma espécie de backlash. ${ }^{6}$ Simultaneamente, também chama atenção que exista, dentre essas violências consideradas, uma operação comum que articula humilhação e intolerância.

Dois artigos focalizam as respostas feministas a essas violências. Neles temos densas reflexões teórico-metodológicas a partir das ferramentas analíticas oferecidas pelas abordagens feministas. Mas também apontamentos importantes acerca das mudanças nas estratégias de atuação dos feminismos. Em "\#queroviajarsozinhasemmedo': novos registros das articulações entre gênero, sexualidade e violência no Brasil", Adriana Piscitelli (2017) tematiza a relação entre feminismos e violência a partir de casos que envolvem mulheres turistas. Toma como ponto de partida a mobilização online em torno do desaparecimento e da morte de duas jovens turistas argentinas no Equador em 2016. Essas reações tiveram lugar no âmbito do que no Brasil foi denominado "primavera feminista". O artigo explora questões metodológicas a serem enfrentadas em estudos sobre as relações entre gênero, violência $e$ turismo e levanta dois pontos vinculados ao debate mais amplo sobre as relações entre gênero, sexualidade e violência. $\mathrm{O}$ primeiro remete às condições que tornam certos registros da violência particularmente relevantes para os feminismos. O segundo ponto se refere às ferramentas analíticas que as abordagens teóricas feministas oferecem para refletir sobre essas relações.

No artigo “'Poner el cuerpo' en las calles: los enfrentamientos de las activistas feministas y los grupos antiderechos", Mónica Tarducci observa mudanças nas estratégias e performances ativistas no contexto do acirramento de conflitos entre ativistas feministas e militantes católicos nos Encontros Nacionais de Mulheres na Argentina, realizados desde 1986. O ativismo católico marca presença nos encontros a partir de 1997. Em resposta à atuação de lideranças e militantes católicos e à

\footnotetext{
6 A relação entre backlash e violências públicas tem sido o foco de investimento analítico de Maria Filomena Gregori.
} 
repressão policial por ocasião das marchas pelas ruas com as quais são finalizados os encontros, os protestos feministas passam a ter novas formas, que incluem a exibição do corpo nu e o uso de violência, frente a um "inimigo" que também "põe o corpo" defendendo o que considera sagrado.

O conjunto final de textos aborda a positividade dos discursos sobre gênero, sexualidade e violência como dispositivos de produção de sujeitos inteligíveis para as políticas de Estado. $\mathrm{O}$ artigo de Isadora Lins França (2017), "Refugiados LGBTI": direitos e narrativas entrecruzando gênero, sexualidade e violência", aborda a articulação entre os chamados direitos sexuais e os direitos relacionados ao refúgio, no marco dos direitos humanos, na produção da categoria "refugiados LGBTI". A categoria tem sido usada para designar solicitantes que procuram fazer uso da possibilidade de reconhecimento do status de refugiado com base na orientação sexual ou identidade de gênero. A autora discute as relações entre gênero, sexualidade $e$ violência $e$ o entrecruzamento de narrativas sobre violência produzidas por diversos atores relacionados ao mundo institucional do refúgio $e$ pelos próprios solicitantes na Espanha e no Brasil. O debate sobre violência e processos de produção de verdade em relação à sexualidade e ao refúgio atravessa a reflexão e serve de base para a análise das narrativas apresentadas no artigo

$\mathrm{O}$ artigo "A reivindicação da violência: gênero, sexualidade e a constituição da vítima", de Roberto Efrem Filho (2017), discute como as relações de gênero e de sexualidade operam na constituição de narrativas sobre violência e como, por sua vez, a reivindicação narrativa da violência perfaz relações de gênero $e$ sexualidade. A partir da análise de narrativas acionadas por mulheres que se mobilizaram por justiça no caso de uma jovem cujo desaparecimento envolvia seu estupro e assassinato, o autor formula três postulados. Em primeiro lugar, a "luta por justiça" requer, de antemão, disputar a legitimidade da vítima como tal. Assim, o acionamento de imagens de brutalidade pelos movimentos sociais contribui para forjar tais corpos como vitimados. Em segundo lugar, a publicização da intimidade da dor 
e do sofrimento opera na legitimação de denúncias, denunciantes e vítimas pelo acionamento de noções de gênero ligadas, entre outras, à maternidade. Em terceiro lugar, as reivindicações narrativas da violência tendem a acionar $e$ atualizar convenções de gênero e de sexualidade, como as que se dão em torno da "prostituição" e do "tráfico de pessoas", recolocando em tensão convenções morais acerca da sexualidade.

As recentes conquistas democráticas e atuais disputas em torno da regulação da sexualidade e de outras fronteiras somáticomorais se inscrevem em um amplo processo de secularização, de produção de novos sujeitos e de politização. Não obstante, os intensos compromissos públicos e íntimos que essas lutas geram, bem como o caráter ritual das manifestações desses sujeitos e disputas, nos fazem interrogar as oposições e dicotomias sobre as quais sua interpretação convencionalmente se monta. Diante de tópicos de indubitável atualidade, o conjunto de textos reunidos para este dossiê busca explorar o reverso analítico de uma trama frequentemente enclausurada nos termos de uma contenda agonística - passo imprescindível para a reconstrução de uma agenda de pesquisa que explore as complexas conexões entre sexualidade, moralidade e política por trás de cada convicção, de cada objeto de conhecimento ou de luta.

Regina Facchini ${ }^{7}$

Horacio Sívori ${ }^{8}$

\footnotetext{
7 Pesquisadora do Núcleo de Estudos de Gênero Pagu e professora dos programas de pósgraduação em Ciências Sociais e em Antropologia Social da Universidade Estadual de Campinas (Unicamp). Atualmente é bolsista de produtividade (nível 2) do CNPq e diretora regional sudeste da ABA. São Paulo, Brasil. re.facchini@gmail.com

8 Professor Adjunto do Departamento de Ciência Humanas, Sociais e Saúde do Instituto de Medicina Social, Universidade do Estado do Rio de Janeiro (IMS/UERJ), onde integra o quadro do Programa de Pós-Graduação em Saúde Coletiva e coordena o Centro LatinoAmericano em Sexualidade e Direitos Humanos (CLAM). Rio de Janeiro, Brasil. hfsivori@gmail.com
} 


\section{Referências bibliográficas}

AlmeidA, Heloisa Buarque de. De médico e de monstro: Disputas em torno das categorias de violência sexual no caso Abdelmassih. cadernos pagu (50), Campinas-SP, Núcleo de Estudos de GêneroPagu/Unicamp, 2017.

AlmEIDA, Ronaldo de. A onda quebrada: evangélicos e conservadorismo. cadernos pagu (50), Campinas-SP, Núcleo de Estudos de GêneroPagu/Unicamp, 2017.

Alvarez, Sonia E. Para além da sociedade civil: reflexões sobre o campo feminista. cadernos pagu (43), Campinas-SP, Núcleo de Estudos de Gênero-Pagu/Unicamp, 2014, pp.13-56.

ARIZA, Lucia. La regulación de las tecnologías reproductivas y genéticas en Argentina: análisis del debate parlamentario. cadernos pagu (50), Campinas-SP, Núcleo de Estudos de Gênero-Pagu/Unicamp, 2017.

CARRARA, Sérgio. A antropologia e o processo de cidadanização da homossexualidade no Brasil. cadernos pagu (47), Campinas-SP, Núcleo de Estudos de Gênero-Pagu/Unicamp, 2016, e164717.

CARVAlHO, Marcos Castro; SívoRI, Horacio. Conservadorismo religioso, gênero e sexualidade na política educacional brasileira. cadernos pagu (50), Campinas-SP, Núcleo de Estudos de GêneroPagu/Unicamp, 2017.

CORRÊA, Mariza. Do feminismo aos estudos de gênero no Brasil: um exemplo pessoal. cadernos pagu (16), Campinas-SP, Núcleo de Estudos de Gênero-Pagu/Unicamp, 2001, pp.13-30.

CUTULI, María Soledad. La travesti permitida y la narcotravesti: imágenes morales en tensión. cadernos pagu (50), Campinas-SP, Núcleo de Estudos de Gênero-Pagu/Unicamp, 2017.

EFREM FILHO, Roberto. A reivindicação da violência: gênero, sexualidade e a constituição da vítima. cadernos pagu (50), Campinas-SP, Núcleo de Estudos de Gênero-Pagu/Unicamp, 2017.

FACCHINI, Regina; FERREIRA, Carolina Branco de Castro. Feminismos e violência de gênero no Brasil: apontamentos para o debate. Cienc. Cult., vol. 68, n 3, São Paulo, 2016, pp.04-05. 
FACCHINI, Regina; FRANCA, Isadora Lins. Apresentação. cadernos pagu (36), Campinas-SP, Núcleo de Estudos de Gênero-Pagu/Unicamp, 2011, pp.7-24.

FerreirA, Carolina Branco de Castro. Feminismos web: linhas de ação e maneiras de atuação no debate feminista contemporâneo. cadernos pagu (44), Campinas-SP, Núcleo de Estudos de GêneroPagu/Unicamp, 2015, pp.199-228.

FRANÇA, Isadora Lins. "Refugiados LGBTI": direitos e narrativas entrecruzando gênero, sexualidade e violência. cadernos pagu (50), Campinas-SP, Núcleo de Estudos de Gênero-Pagu/Unicamp, 2017.

GREGORI, Maria Filomena. Violence and gender: political paradoxes, conceptual shifts. Vibrant, vol. 7, n 2, 2010, pp.216-235.

LUNA, Naara. A criminalização da "ideologia de gênero": uma análise do debate na Câmara dos Deputados sobre diversidade sexual em 2015. cadernos pagu (50), Campinas-SP, Núcleo de Estudos de GêneroPagu/Unicamp, 2017.

MACHADO, Lia Zanotta. Feminismos brasileiros nas relações com o Estado. Contextos e incertezas. cadernos pagu (47), Campinas-SP, Núcleo de Estudos de Gênero-Pagu/Unicamp, 2016, e16471.

MACHADO, Lia Zanotta. O aborto como direito e o aborto como crime: o retrocesso neoconservador. cadernos pagu (50), Campinas-SP, Núcleo de Estudos de Gênero-Pagu/Unicamp, 2017.

PISCITELLI, Adriana. "\#queroviajarsozinhasemmedo": novos registros das articulações entre gênero, sexualidade e violência no Brasil. cadernos pagu (50), Campinas-SP, Núcleo de Estudos de GêneroPagu/Unicamp 2017.

Silva, Ana Paula da; BlancheTte, Thaddeus Gregory. Por amor, por dinheiro? Trabalho (re)produtivo, trabalho sexual e a transformação da mão-de-obra feminina. cadernos pagu (50), Campinas-SP, Núcleo de Estudos de Gênero-Pagu/Unicamp 2017.

TARDUCCI, Mónica. "Poner el cuerpo" en las calles: los enfrentamientos de las activistas feministas y los grupos anti-derechos. cadernos pagu (50), Campinas-SP, Núcleo de Estudos de Gênero-Pagu/Unicamp 2017. 
VAgGione, Juan Marco. Laicidad y sexualidad. Ciudad de México, UNAM, 2013.

VAGgione, Juan Marco. La Iglesia Católica frente a la política sexual: la configuración de una ciudadanía religiosa. cadernos pagu (50), Campinas-SP, Núcleo de Estudos de Gênero-Pagu/Unicamp 2017. 